\title{
Hubungan Antara Kekuatan Otot Lengan Dan Koordinasi Mata Tangan Dengan Ketepatan Servis Forehand Tinggi Dalam Permainan Bulutangkis Peserta Ekstra Kurikuler di SMKN 3 Kota Sukabumi Tahun 2020
}

\author{
The Relationshi Between Arm Muscle Strength And Hand Eye Coordination \\ With HighForehand Service Accuracy In Badminton Games \\ Extra-Curricular Participants at SMKN 3 Sukabumi City in 2020
}

\author{
M.Fatwa Efendi
}

Universitas Muhammadiyah, Kota Sukabumi, Jawa Barat, Indonesia moch.fatwa42@gmail.com

\begin{abstract}
ABSTRAK
Penelitian ini bertujuan untuk mengetahui hubungan antara kekuatan otot lengan dan koordinasi mata tangan pada peserta ekstrakurikuler di SMK Negeri 3 Sukabumi dilatar belakangi oleh, pentingnya peranan kekutan otot lengan dan koordinasi mata tangan dalam permainan bulutangkis.

Penelitian ini menggunakan metode kuantitatif dengan teknik tes dan pengukuran. Sampel peneitian adalah peserta ekstrakurikuler di SMK Negeri 3 Sukabumi yang berjumlah 15 orang, dengan teknik pengambilan sampel menggunakan sampling Purposive. Instrumen yang digunakan dalam penelitian ini meliputi: (1). Tes kekuatan otot lengan (2). Tes koordinasi mata tangan (3). Tes ketepatan pukulan servis forehand. Teknik analisis data menggunakan teknik kuantitatif dengan analisis statistik korelasi ganda yaitu mencari besarnya hubungan dan konstribusi dua variabel bebas (X) atau lebih secara simultan (bersama-sama) dengan varibel terikat (Y), menggunakan spss dan rumus korelasi ganda,

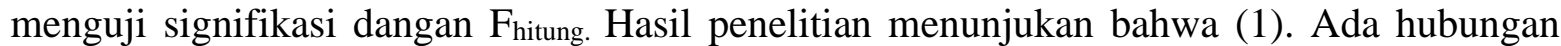
yang signifikan antara kekuatan otot lengan (X1) dan ketepatan pukulan servis forehand (Y). (2). Ada hubungan yang signifikan antara koordinasi mata tangan (X2) dan ketepatan pukulan servis forehand (Y). (3). Ada hubungan yang signifikan antara kekuatan otot lengan (X1) dan koordinasi mata tangan (X2) dengan ketepatan pukulan servis forehand (Y).

Berdasarkan hasil perhitungan menggunakan teknik korelasi ganda diperoleh hasil $F_{\text {hitung }}$ lebih besar dari pada $F_{\text {tabel, yaitu }} F_{\text {hitung }}(20,21)>F_{\text {tabel }}(3,11)$ dengan taraf signifikan 0,05 maka $\mathrm{H}_{1}$ ditolak artinya terdapat hubungan antara kekuatan otot lengan dan koordinasi mata tangan dengan ketepatan pukulan servis forehand dalam permainan bulutangkis pada peserta ekstrakurikuler SMK Negeri 3 Sukabumi.

Berdasarkan hasil korelasi $\mathrm{X}_{1}, \mathrm{X}_{2}$ terhadap $\mathrm{Y}$ diperoleh $\mathrm{F}_{\text {hitung }}$ lebih besar dari pada $F_{\text {tabel, }}$ yaitu $F_{h i t u n g}(20,21)>F_{\text {tabel }}(3,11)$ dengan taraf signifikansi 0,05 . Dengan mendapatkan hasil perhitungan $\mathrm{R}_{\mathrm{X} 1 \mathrm{X} 2 \mathrm{Y}}$ sebesar 0,877 dengan kategori tergolong kuat dan tinggi. Dan konstruksi secara simultan $\mathrm{R}^{2} \times 100 \%=0,877^{2} \times 100 \%=76,9 \%$ dan sisanya $23,1 \%$. Artinya penguasaan kekuatan otot lengan dan koordinasi mata tangan memberikan kontribusi dengan
\end{abstract}


ketepatan pukulan servis forehand dalam permainan bulutangkis sebesar 76,9\% dan sisanya $23,1 \%$ oleh variabel lain.

Kata kunci : Kekuatan Otot Lengan, Kekuatan Koordinasi Mata Tangan, Ketepatan Pukulan servis forehand.

\begin{abstract}
This study aims to determine the relationship between arm muscle strength and hand eye coordination in extracurricular participants at SMK Negeri 3 Sukabumi against the background, the importance of the role of arm muscle strength and hand eye coordination in badminton.

This research uses quantitative methods with test and measurement techniques. The research sample was 15 extracurricular participants in SMK Negeri 3 Sukabumi, with a sampling technique using purposive sampling. The instruments used in this study include: (1). Arm muscle strength test (2). Hand eye coordination test (3). Test accuracy forehand service punches. Data analysis techniques using quantitative techniques with multiple correlation statistical analysis that is looking for the magnitude of the relationship and the contribution of two independent variables (X) or more simultaneously (together) with the dependent variable (Y), using SPSS and multiple correlation formulas, testing the significance of Fcount. The results showed that (1). There is a significant relationship between arm muscle strength (X1) and the accuracy of the forehand service (Y). (2). There is a significant relationship between hand eye coordination (X2) and the accuracy of the forehand service $(Y)$. (3). There is a significant relationship between arm muscle strength $(X 1)$ and hand eye coordination (X2) with the accuracy of the forehand service (Y).

Based on the results of calculations using the multiple correlation technique, the Fcount result is greater than Ftable, namely Fcount (20.21)> Ftabel (3.11) with a significant level of 0.05 then $H 1$ is rejected, meaning that there is a relationship between arm muscle strength and hand eye coordination with the accuracy of forehand service punches in badminton games on extracurricular participants of SMK Negeri 3 Sukabumi.

Based on the results of the correlation X1, X2 against $Y$ obtained Fcount greater than Ftable, namely Fcount (20.21)> Ftable (3.11) with a significance level of 0.05. By getting the RX1X2Y calculation results of 0.877 with the category classified as strong and high. And simultaneous construction $R 2 \times 100 \%=0.8772 \times 100 \%=76.9 \%$ and the remaining 23.1\%. This means that mastery of arm muscle strength and hand eye coordination contribute to the accuracy of forehand service punches in badminton by $76.9 \%$ and the remaining $23.1 \%$ by other variables.

Keywords: Arm Muscle Strength, Hand Eye Coordination Strength, Forehand Service Accuracy.
\end{abstract}

\title{
PENDAHULUAN
}




\section{Latar Belakang}

Permainan bulutangkis merupakan salah satu cabang olahraga yang telah berkembang dan memasyarakat,baik di sekolah-sekolah maupun kedesa-desa. Berdasarkan dengan perkembangan jaman, untuk saat ini servis tidak hanya asal memukul shuttlecock melewati net dengan keras. Namun digunakan juga untuk memperoleh point ataupun disebut juga dengan penyerangan. Servis merupakan salah satu teknik dalam permainan bulutangkis. Dalam permainan bulutangkis tehnik dasar yang harus dimiliki adalah pegangan raket, footwork, servis, underhand, overhead clearllob, round the head clear, smash, dropshot, netting, drive.

Dalam pukulan servis forehand tinggi banyak faktor-faktor yang mempengaruhi pada saat pukulan, seperti kekuatan otot lengan yang harus kuat pada saat memukul, dengan koordinasi mata tangan yang harus akurat agar pukulan tepat mengenai sasaran pada saat pukulan,, sehingga koordinasi mata tangan dapat berkontraksi dengan otot lengan secara bersama sama sehingga menghasilkan daya yang lebih maximal dan tepat sehingga pukulan servis forehand tinggi dapat maksimal jatuh digaris belakang.

Setelah peneliti melakukan dan pengamatan dan observasi di salah satu ekstrakurikuler di SMK Negeri 3 Kota Sukabumi pada hari, 12 maret 2019, pada saat pelatih memberikan latihan bulutangkis, menurut beliau sebagian besar peserta ekstrakurikuler kurang mampu dalam menguasai pukulan servis forehand tinggi, menurut beliau di karenakan pada saat pukulan servis forehand tinggi, kekuatan otot lengan dan koordinasi mata tangan bahwa kurang maximal sehingga perkenaan shuttlecock pada permukaan raket tidak tepat, hal ini yang mengakibatkan pukulan menjadi rendah, karena dalam pukulan servis forehand tinggi kekuatan otot lengan dan koordinasi mata tangan sangat berhubungan dan berpengaruh sebagai otot pertama dan konsentrasi yang berkonstribusi ataupun berkontraksi dalam pukulan ini. Dengan permasalahan seperti itu, menyebabkan pelatih dalam memberikan pelatihan bulutangkis akan terhambat. Berdasarkan permasalahan tersebut, peneliti sangat tertarik untuk meneliti dengan judul Hubungan Antara Kekuatan Otot Lengan dengan 
Koordinasi Mata Tangan Terhadap Ketepatan Pukulan Servis Forehand Tinggi Dalam Permainan Bulutangkis Pada Pada Ekstrakurikuler di SMK Negeri 3 Kota Sukabumi.

\section{Rumusan Masalah}

Apakah terdapat hubungan yang signifikan antara kekuatan otot lengan dengan ketepatan pukulan servis forehand tinggi dalam permainan bulutangkis?

Apakah terdapat hubungan yang signifikan antara koordinasi mata tangan dengan ketepatan pukulan servis forehand tinggi dalam permainan bulutangkis?

Apakah terdapat hubungan yang signifikan antara kekuatan otot lengan dengan koordinasi mata tangan terhadap ketepatan pukulan servis forehand tinggi dalam permaina bulutangkis?

\section{Tujuan Penelitian}

Untuk mengetahui dan menganalisa hubungan yang signifikan antara Kekuatan otot lengan dengan ketepatan pukulan servis forehand tinggi dalam permainan bulutangkis. Untuk mengetahui dan menganalisa hubungan yang signifikan antara koordinasi mata tangan dengan ketepatan pukulan servis forehand tinggi dalam permainan bulutangkis.

Untuk mengetahui dan menganalisa hubungan yang signifikan antara Kekuatan otot lengan dengan koordinasi mata tangan terhadap ketepatan pukulan servis forehand tinggi dalam permainan bulutangkis 
Pengertian Bulutangkis menurut Rahmani, M. (2014: 71) yaitu di Indonesia terdapat permainan yang sangat terkenal di masyarakat. Permainan bulutangkis ini merupakan permainan yang menggunakan alat yang dinamakan raket dan shuttlecock, yang dimainkan oleh 2 orang pemain atau 4 orang pemain. Cara memainkan permainan ini adalah dengan memukul shuttlecock dengan menggunakan raket dengan target melewati net yang terletak di tengah lapangan. Jatuhnya shuttlecock harus tepat berada di daerah lawan, begitu juga sebaliknya.

Aksan (2012: 14) menerangkan bahwa bulutangkis merupakan olahraga raket yang dimainkan oleh dua orang (untuk tunggal) atau dua pasangan (untuk ganda) yang mengambil posisi berlawanan di bidang lapangan yang dibagi dua oleh sebuah jaring (net). Para pemain meraih angka dengan memukul bola permainan berupa shuttlecock dengan raket melewati net dan jatuh di bidang permainan lawan. Tiap pemain atau pasangan hanya boleh memukul shuttlecock sekali sebelum melewati net. Sebuah reli berakhir jika menyentuh lantai atau menyentuh tubuh seorang pemain.

Sedangkan dalam pertandingan bulutangkis terdapat beberapa teknik yang mesti dikuasai oleh pemain, salah satunya adalah teknik pukulan servis forehand tinggi. Menururt dalam (Nurjamilah, B. 2018: 19) mengemukakan bahwa servis panjang dilakukan dengan memukul shuttle dari bawah dan diarahkan ke bagian belakang atas lapangan permainan lawan. Biasanya dilakukan oleh pemain tunggal,sehingga sering dinamakan dengan deep single servis Jenis servis ini terutama digunakan dalam permainan tunggal. Shuttlecock harus dipukul dengan menggunakan tenaga penuh agar shuttlecock melayang tinggi dan jatuh tegak harus di bagian belakang garis lawan. Saat memukul shuttlecock kedua kaki terbuka selebar pinggul dan kedua telapak kaki senantiasa kontak dengan lantai. Pukulan ini akan memaksa lawan untuk bergerak mundur kearah sisi belakang lapangan sehingga lawan akan memukul dengan keadaan terdesak..

Servis foreheand tinggi merupakan pukulan untuk memberikan tekanan dari kepada lawan sehinga kita bisa untuk berdiri dengan siap pada saat permainan agar lawan banyak menghabiskan tenaga dan juga untuk bersiap pada menyerang pada saat menerima pukulan dari lawan. Pukulan ini sangat berpengaruh sekali saat permainan karena pada saat 
melakukan pukulan servis forehand tinggi. harus banyak mengeluarkan tenaga yang besar dan konsentrasi yang sangat tinggi.

Menurut Iskandar, Z. Adisapoetra dkk (dalam Yusman, F.S. 2016: 27) bahwa "kekuatan otot lengan adalah kemampuan otot atau sekelompok otot untuk melakukan satu kali kontraksi secara maksimal melawan tambahan atau beban". Kekuatan adalah komponen kondisi fisik seseorang tentang kemampuanya dalam mempergunakan otot untuk menerima beban suatu bekerja. Kekuatan merupakan suatu komponen fisik yang menjadi syarat dasar yang harus dimiliki seseorang untuk dapat melakukan aktivitas ataupun untuk dapat mencapai prestasi. Karena kekuatan merupakan faktor pertama yang mendukung keberhasilan pukulan yang baik. Dan lengan adalah bagian tubuh yang digunakan untuk melakukan pukulan servis forehand tinggi. Maka kekuatan otot lengan harus mempunyai kekuatan yang kuat dan dapat memaksimalkan pukulan servis forehand tinggi dapat dilakukan dengan baik dan tepat sasaran. Sedangkan Sedangkan menurut Widiastuti (dalam Dede, K.A. 2018: 16) "Koordinasi yaitu kemampuan untuk melakukan gerakan atau kerja dengan tepat dan efisien, koordinasi menyatakan hubungan harmonis berbagai faktor yang terjadi pada suatu gerakan kemampuan koordinatif merupakan dasar yang baik bagi kemampuan belajar yang bersifat sensomotorik makin baik bagi tingkat kemampuan koordinasi, akan makin cepat dan efektif pula gerakan yang sulit dapat dilakukan".

\section{METODE PENELITIAN}

\section{Tempat dan Waktu Penelitian}

Penelitian ini dilakukan di SMK Negeri 3 Kota Sukabumi. Waktu penelitian ini dilaksanakan pada bulan Maret 2019.

\section{Populasi dan Sampel Penelitian}


Jumlah populasi yang peneliti gunakan adalah 15 peserta ekstrakurikuler SMK Negeri 3 Kota Sukabumi yang berjumlah 28 siswa. Dalam penelitian ini peneliti menggunakan sampling Purposive. Menurut sugiono 2018 (84-85) “sampling Purposive adalah teknik penentuan sample dengan pertimbangan tertentu. Dalam penelitian ini penulis mengambil jumlah sample 15 dari seluruh peserta yang berjumlah 28 peserta. Diambil yang sudah bisa menguasai teknik bulutangkis sebanyak 15 orang. Dan 15 orang lainnya belum bisa menguasai teknik bulutangkis karena sampling purposive lebih mengutamakan sample yang ahli. Sampel ini lebih cocok digunakan untuk penelitian kualitatif, atau penelitian-penelitian yang tidak melakukan keneralisasi”.

\section{Desain Penelitian}

Desain penelitian yang menjadi variabel bebas adalah kekuatan otot lengan (X1) dan koodinasi mata tangan (X2) dan yang menjadi variabel terikatnya adalah ketepatan pukulan servis forehand tinggi(Y). Sedangkan penelitian menggunakan metode kuantitatif dengan rancangan analisis korelasional yaitu untuk mengetahui tingkat keeratan hubungan antara dua variabel atau lebih yaitu antara variabel terikat (dependent) dan variabel bebas (independent). Sedangkan analisis data yang digunakan dalam penelitian ini menggunakan teknik pengumpulan data statistik korelasi ganda dan spss.

\section{Hipotesis Statistik}

$\mathrm{H}_{1}: \mathrm{r} \neq 0$

$\mathrm{H}_{0}: \mathrm{r}=0$

Artinya :

$\mathrm{H}_{1}$ : Ada hubungan yang signifikan antara kekuatan otot lengan dengan koordinasi mata tangan terhadap ketepatan pukulan servis forehand tinggi dalam permainan bulutangkis pada siswa kelas X SMKN 3 Kota Sukabumi..

Ho : Tidak ada hubungan yang signifikan antara kekuatan otot lengan dengan koordinasi mata tangan terhadap ketepatan pukulan servis forehand tinggi dalam permainan bulutangkis pada siswa kelas X SMKN 3 Kota Sukabumi. 


\section{HASIL DAN PEMBAHASAN}

\section{Hasil Penelitian}

Berdasarkan hasil perhitungan menggunakan teknik korelasi ganda diperoleh hasil $F_{\text {hitung }}$ lebih besar dari pada $F_{\text {tabel, yaitu }} F_{\text {hitung }}(20,21)>F_{\text {tabel }}(3,11)$ dengan taraf signifikan 0,05 maka $\mathrm{H}_{1}$ ditolak artinya terdapat hubungan antara kekuatan otot lengan dan koordinasi mata tangan dengan ketepatan pukulan servis forehand dalam permainan bulutangkis pada peserta ekstrakurikuler SMK Negeri 3 Kota Sukabumi.

Berdasarkan hasil korelasi $\mathrm{X}_{1}, \mathrm{X}_{2}$ terhadap $\mathrm{Y}$ diperoleh $\mathrm{F}_{\text {hitung }}$ lebih besar dari pada $F_{\text {tabel, yaitu }} F_{\text {hitung }}(20,21)>F_{\text {tabel }}(3,11)$ dengan taraf signifikansi 0,05. Dengan mendapatkan hasil perhitungan $\mathrm{R}_{\mathrm{X} 1 \mathrm{X} 2 \mathrm{Y}}$ sebesar 0,877 dengan kategori tergolong kuat dan tinggi. Dan konstruksi secara simultan $\mathrm{R}^{2} \times 100 \%=0,877^{2} \times 100 \%=76,9 \%$ dan sisanya $23,1 \%$. Artinya penguasaan kekuatan otot lengan dan koordinasi mata tangan memberikan kontribusi dengan ketepatan pukulan servis forehand dalam permainan bulutangkis sebesar 76,9\% dan sisanya $23,1 \%$ oleh variabel lain.

\section{Pembahasan}

Dalam permainan bulutangkis banyak hal yang dapat mempengaruhi hasil kerja dalam permainan tersebut, contohnya hubungan dari kekuatan otot lengan dengan koordinasi mata tangan. Secara lebih spesifik bagian-bagian tubuh yang terlibat secara langsung saat melakukan pukulan servis forehand tinggi adalah kekuatan otot lengan dengan koordinasi mata tangan. kedua kondisi fisik ini sangat berhubungan sekali dalam keberhasilan melakukan pukulan servis forehand tinggi untuk menghasilkan pukulan yang akurat dan tepat sasaran. Dalam penelitian peserta terlihat antusias untuk mengikuti penelitian namun ada beberapa siswa terlihat tidak bersemangat dalam mengikuti penelitian. Penelitian ini membutuhkan 15 sampel dengan jumlah peserta dari jumlah populasi sebanyak 28 orang.dari sample tersebut laki-laki berjumlah 11 peserta dan perempuan 4 peserta. 
1. Tes kekuatan otot lengan

Tes kekuatan otot lengan berupa tes push up dengan kemampuan masingmasing peserta dalam melakukan tes push up rata-rata siswa dapat melakukan 33,3. Dengan peserta yang melakukan push up terbanyak 40 yang bernama Dick dan rian,untuk nilai terendah melakukan push up sebanyak 23 kali.

2. Tes koordinasi mata tangan

Tes koordinasi mata tangan berupa tes lempar tangkap menggunakan bola tenis lapangan dengan menggunakan target dan berjarak 2,5 meter sebanyak 10 kali dua kali ulang lemparan. lemparan dalam mencapai target Dengan total hasil maksimal yang harus di lakukan siswa 20 kali. Untuk jumlah nilai terbanyak diperoleh yang bernama Dicky, Ipan, dan Fajri dengan jumlah 18 kali mencapai target. Dan untuk jumlah terkecil sebesar 7 kali mencapai target.

3. Tes Servis forehand tinggi

Tes servis forehand tinggi dengan menggunakan alat berupa raket,shuttlecock dan tali.tali digunakan sebagai kotak target untuk mengetahui nilai yang tertinggi dengan jarak yang lebih jauh.untuk nilai tertinggi di raih dengan nilai 37 yang bernama Dicky dan nilai terendah dengan nilai 14.

\section{KESIMPULAN}

Kesimpulan pada penelitian ini selaras dengan pokok pertanyaan dalam penelitian yang terdapat dalam bab 1 yaitu bahwa terdapat hubungan yang signifikan antara kekuatan otot lengan dengan ketepatan servis forehand tinggi, koordinasi mata tangan dengan ketepatan servis forehand tinggi, dan kekuatan otot lengan dengan koordinasi mata tangan terhadap ketepatan servis forehand tinggi.hal itu berdampak positif bagi perkembangan peserta dalam ekstrakurikuler.untuk membantu ketepatan dalam melakukan servis forehand tinggi.

\section{DAFTAR PUSTAKA}

Aksan, H. (2012). Mahir Bulu Tangkis. Bandung: Nuansa Cendekia. 
Barakat, Nurjamilah. (2018). Hubungan Antara Kekuatan Otot Lengan Dan Fleksibilitas Pergelangan Tangan Terhadap Ketepatan Servis Long Forehand Di Ekstrakurikuler Bulutangkis SMA Negeri 1 Kota Sukabumi. Skripsi Sarjana Pada FKIP UMMI: Sukabumi Tidak Diterbitkan.

Agustinin, D. Khoirunnisa. (2018). Hubungan Kekuatan Otot Lengan Dan Koordinasi Mata Tangan Terhadap Ketepatan Shooting Dalam Olahraga Pentaque Di Klub Kota Sukabumi. Skripsi Sarjana Pada FKIP UMMI: Sukabumi Tidak Diterbitkan.

Rahmani, M. (2014). Buku Super Lengkap Olahraga. Jakarta Timur: Dunia Cerdas.

Yusman, F.S. (2016). Hubungan Antara Koordinasi Mata Tangan dan Kekuatan Otot Lengan Terhadap Keterampilan Push (Dorongan) Peserta Ekstrakurikuler Hoki Smk PGRI 1 Kota Sukabumi. Sukabumi: Tidak diterbitkan. 